\title{
Combination Tones in Violins
}

\author{
Angela LOHRI ${ }^{(1)}$, Sandra CARRAL ${ }^{(2)}$, Vasileios CHATZIIOANNOU $^{(2)}$ \\ University of Music and Performing Arts Vienna \\ (1) International Centre of Harmonics \\ (2) Institute of Musical Acoustics \\ Anton-von-Webern-Platz 1, 1030 Vienna, Austria \\ e-mail: angela.lohri@gmx.ch \\ (received January 11, 2011; accepted June 22, 2011)
}

In this study we investigate the appearance of combination tones in violins. Most authors in recent times have emphasised that combination tones occur inside the ear exclusively (intra-aural). This assumption will be subjected to scrutiny based on evidence found in an empirical study in which combination tones were measured outside the ear (extra-aural).

Measurements were performed in which a violinist played two tones of a particular musical interval simultaneously. This was recorded and subsequently analysed using a Fourier Transformation. In addition to the partial tones of the primary interval, the resulting spectrum showed frequencies corresponding to combination tones. Similar measurements on the viola and violoncello also revealed the existence of extra-aural combination tones. Such frequencies may influence the timbre of simultaneous intervals played on string instruments. In another experiment the violin was excited using an electrodynamic mini-shaker with the aim of localising the origin of extra-aural combination tones. A newly devised tone matrix was used as a theoretical approach which computes all potential combination tones that may occur between any pair of partial tones. The detailed analysis of musical intervals by both the frequency spectrum and the tone matrix shows characteristic mirror and point symmetries in the partial tone structure. The discussion focuses mainly on the audibility of extra-aural combination tones and on 'the combination tone 1'. This research opens up new perspectives and questions relevant for interpreters, composers, violin makers and violin acousticians.

Keywords: combination tones, extra-aural, intra-aural, string instruments, measurements of simultaneous intervals, nonlinearity, virtual pitch.

\section{Introduction}

In the 1900's the phenomenon of combination tones became generally known as "psychoacoustic combination tones" or "subjective combination tones". Most 
modern textbooks emphasise that combination tones occur inside the ear (intraaural) exclusively. In this study this idea will be discussed on the base of measurements of bowed string instruments. To make progress in the discussion about the real nature of combination tones, this research demands an interdisciplinary approach. Therefore, the authors put great importance on collaboration and comprehension between their disciplines, which are acoustics, mathematics and music.

This paper is organised as follows: The discovery and history of combination tones is discussed in this Section. In Sec. 2 the formulation of the problem is analysed including the derivation of a tone matrix. Section 3 describes a set of experiments carried out on several bowed string instruments and the outcomes of the measurements are discussed in Sec. 4.

\subsection{Tartini and Helmholtz}

The phenomenon of combination tones was detected by the famous Italian violinist and music pedagogue Giuseppe Tartini in 1714. He discovered that two musical tones played simultaneously, no matter if on one single instrument or on two different instruments, generated a third tone, in Tartini's words "terzo suono". He observed that, lying lower than the played interval, the third tone acted like a bass giving the interval a third dimension, a subtle harmonic context (TARTini, 1754, pp. 13-17). Tartini, not only a genius musician but also a genius thinker, wrote down the detected correlations between mathematics and the third tones in his book Trattato di musica secondo la vera scienza dell'armonia ("Treatise on Music according to the True Science of Harmony"). His insights about the principles of the third tone had a significant influence on the development of music theory. Tartini's discovery opened up entirely new possibilities of how sound quality can be understood and realized by practising musicians. Il terzo suono served him especially as a tool to control the intonation of intervals and to build entire scales in absolutely precise proportions.

"When I play a double stop on my violin I can physically meet the form of the interval: its physical sign and proof is the third tone which must result. I have thus for myself and for my students the benefit of reliable intonation, and consequently, the benefit of the actual use of the above-mentioned scale, with its precise proportions"(1) [Transl. by Ph. Borer]. Since the middle of the 19th century, the notion of "third tone" has generally been replaced by the term "difference tone" which is a sub-category of the entire family of combination tones.

(1) TARTini, 1754, p. 100: "Io nel mio violino, dove suonando a doppia corda posso incontrar fisicamente la forma dell'intervallo, di cui è segno fisico dimostrativo il tal terzo suono, che deve risultare, ho il vantaggio per me, e per i miei scolari della sicura intonazione, e in conseguenza dell'uso reale della scala suddetta in precisione di ragioni." 
In the 19th century, the third tone was studied more systematically. The term "combination tone", introduced by Vieth in 1805, was then generally adopted (VIETH, 1805, p. 265). About 150 years after the discovery of combination tones by Tartini, Hermann von Helmholtz published his ground-breaking book Die Lehre von den Tonempfindungen ("On the Sensations of Tone") in 1863. Chapter 7 of that book is entirely dedicated to the phenomenon of combination tones. Apart from the detection of summation tones, Helmholtz presented a new and revolutionary explanation of combination tones, today known as 'distortion theory', and performed experiments where he measured extra-aural combination tones (combination tones that are generated outside and independently of the ear). He called them "objective Combinationstöne" ("objective combination tones") (Helmholtz, 1856, p. 498) and demonstrated their existence on a polyphonic siren and on a harmonium applying membranes that began to vibrate if a specific frequency occurred (HeLmHOLTZ, 1863, p. 157).

Helmholtz's new conclusions were accepted universally. Until 1906, inspired by the new theories of Helmholtz, several studies appeared about these "objective combination tones" (Plomp, 1965, p. 1114). Since that time, research about objective combination tones seems to stagnate. Plomp explains: "By the rapid development of electronics in the first decades of this century, the phenomenon of nonlinear characteristics became so familiar that the existence of combination tones lost much of its enigmatic character" (PlomP, 1965, p. 1115). This may be true as far as the aspects of physics are concerned, but regarding music performance, the significance of combination tones has not been sufficiently investigated.

\section{Nonlinear systems and combination tones}

\subsection{Definitions}

\subsubsection{Nonlinear systems}

Combination tones are the product of nonlinear, acoustic transmission systems (EBELING, 2007, p. 36). The human ear or a string instrument are examples of such systems. We are dealing with a nonlinear system if the response of the system to multiple inputs is not equal to the sum of the responses to each input.

\subsubsection{Intra-aural and extra-aural combination tones}

For the purpose of clarity, combination tones that are generated inside the ear will be called "intra-aural", those that occur outside and independently of the ear "extra-aural". Intra-aural combination tones (ICT) have their origin in the human ear, therefore they cannot be detected by a microphone. Accordingly, how intense intra-aural combination tones are perceived varies depending on the individual auditory capacities of the person. In contrast to the intra-aural 
combination tones, extra-aural combination tones (ECT) can be measured as vibrations in the air; they follow physical principles.

\subsubsection{Mathematical expression}

The response of a linear system that is being excited by two frequencies $f_{1}$ and $f_{2}$ contains only the same two frequency components. If the system is nonlinear, based on the 'distortion theory', combination tones may occur at frequencies

$$
k_{1} f_{1} \pm k_{2} f_{2}, \quad k_{1}, k_{2} \in \mathrm{Z} .
$$

Both extra-aural and intra-aural combination tones are generated by the same mechanism, due to a nonlinear system. This is not self-evident considering that a body of a violin is morphologically different from a human ear. The presence of combination tones has been studied extensively by HÄLLSTRÖM (1819; 1832), Ohm (1839), Helmholtz (1856; 1863), Krueger (1900), StumpF (1910), Husmann (1953), Plomp (1965), Zwicker, Feldkeller (1967) and Smoorenburg (1972), and others. Their results show that for simple primary tones the average listener could hear combination tones of the second and third order, this corresponds to the quadratic and cubic distortion of the human ear.

\subsubsection{Difference tones and summation tones}

In order to understand the origin of combination tones, it is important to make the distinction between difference tones and summation tones. HELMHOLTZ (1863, p. 153) defined: "Combinational tones are of two kinds. The first class, discovered by Sorge and Tartini, I have termed differential tones, because their pitch number is the difference of the pitch numbers of the generating tones. The second class of summational tones, having their pitch number equal to the sum of the pitch numbers of the generating tones, were discovered by myself".

Summation tones are difficult to hear because they are subjected to the masking effect of the primary tones, whereas most of the difference tones are not masked because they are lower than the primary tones.

\subsection{Tone matrix}

Summation tones and difference tones can occur between any pair of partial tones. We have devised a special tone matrix to systematically compute all possible combinations between partial tones. Inserting the ratio of a particular musical interval or the frequencies of the interval themselves, the tone matrix computes all potential combination tones that could be generated by this interval (see Fig. 1). This tone matrix shows that the same combination tone can be generated via different partial tone pairs. Inserting the frequency ratio of 


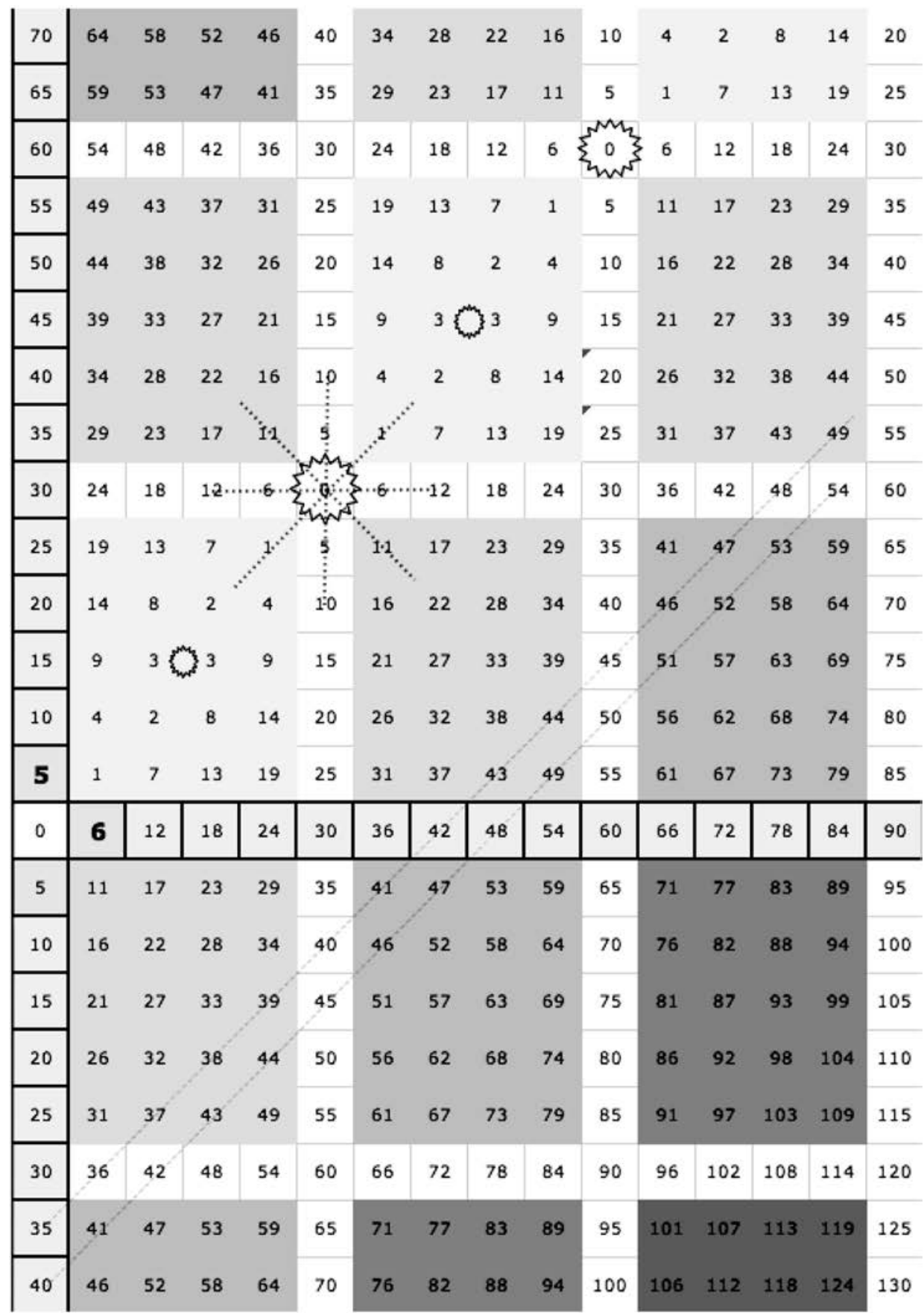

Fig. 1. The example shows the interval 5:6 (minor third). The numbers printed in bold represent the primary tones. The respective harmonics are displayed vertically and horizontally. The difference tones are disposed in the upper quadrant, the summation tones appear in the lower quadrant. 
the primary tones (in Fig. 1 the ratio 5:6 is used, see bold numbers), the matrix computes all possible sums (summation tones) and subtractions (difference tones) between pairs of partial tones.

In music theory the representation of intervals in frequency ratios (or in string length proportions) is fundamental. "In Pythagorean tradition, the quantity expressed by a number corresponds to the quality expressed by a musical tone" (Ph. Borer, personal communication, April 2008). Moreover, operating with simple ratios, interesting structures can be observed in the matrix. Determined by its ratio, each interval generates characteristic point symmetries (see Fig. 1). Looking at Fig. 2, the same symmetries are visible in the corresponding spectrum as well, but changed from point symmetry into mirror symmetry. In Fig. 2, $\mathrm{A} 1, \mathrm{~A} 2, \mathrm{~A} 3 \ldots$ and B1, B2, B3... indicate the two harmonic series generated by the two played notes. Remarkably, these two series coincide with combination tones.

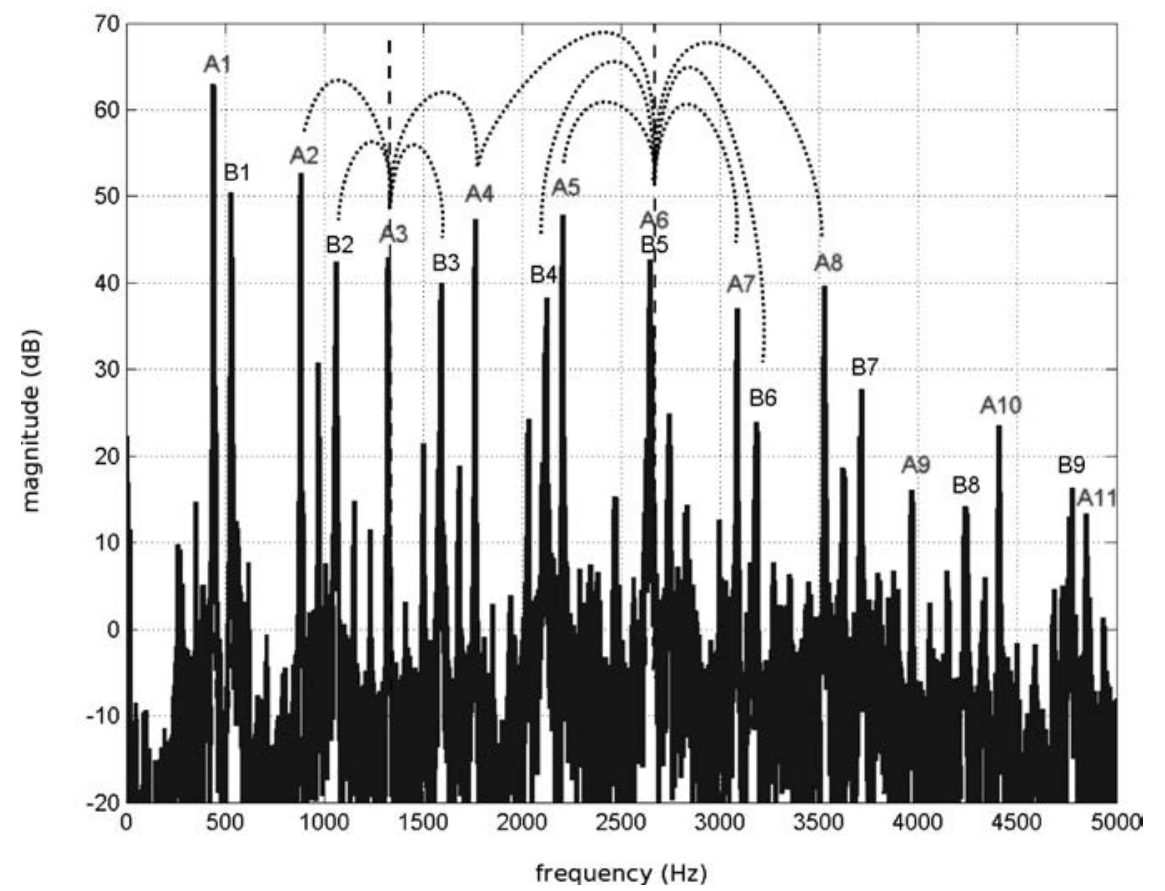

Fig. 2. Spectrum of the interval 5:6 (minor third) played on the violin. The structure of partial tones and combination tones shows characteristic mirror symmetries. More details in (LOHRI, 2010).

\section{Measurements}

In contrast to intra-aural combination tones, research about extra-aural combination tones has been neglected since the early 20 th century. To the best of the 
authors' knowledge, the latest measurements of extra-aural combination tones date from 1906, performed by WAETZMANN (1906). In order to test the assumption that combination tones on the violin exist already outside the ear, a series of measurements have been performed.

\subsection{Methodology}

Two different methods were used in order to obtain experimental evidence of the existence of combination tones. The first one was carried out playing the instrument in the usual way, whereas the second took place under restricted conditions, aiming at studying the response of the instrument.

\subsubsection{Method 1}

In an anechoic chamber, the string player played two notes simultaneously that corresponded to a particular musical interval. The sound was recorded using a microphone (Roga RG-50), positioned near the $f$ holes. A section of approximately two seconds duration was taken from the recorded sound, and its spectrum was calculated using an FFT. To get more information from the measurements we could remove or add following parameters directly on the violin:

A: with free vibrating strings;

B: with sound post/without sound post.

\subsubsection{Method 2}

Instead of a bow, an electrodynamic mini-shaker (Brüel \& Kjær Type 4810) that produced two simultaneous frequencies excited a violin fixed at its neck and ribs. The contact point of the shaker was placed on the corner of the bridge or on the body of the violin near the bridge. The vibrations were measured using an accelerometer fixed on the body next to the bridge to obtain the vibration of the instrument's body. To find out where combination tones originate from, we used violins specially prepared for the measurements. Performing these measurements in a violin maker's studio we were able to change or combine the following parameters:

A: with free vibrating strings/with damped strings;

B: with sound post/without sound post;

C: without strings and without bridge.

\section{Results and discussion}

Subsections 4.1-4.5 expose some intermediate results and perspectives of our ongoing research project. 


\subsection{Measurement results from methods 1 and 2}

With both methods various extra-aural combination tones were detected. Figure 3 shows the spectrum of the interval 5:8 (440 and $704 \mathrm{~Hz}$ ) played on a violin (method 1), where several combination tones can be identified. The excitation of the body of the violin with a shaker (method 2) causes a similar distribution of combination tones compared to that of the recorded sound (see Fig. 4).

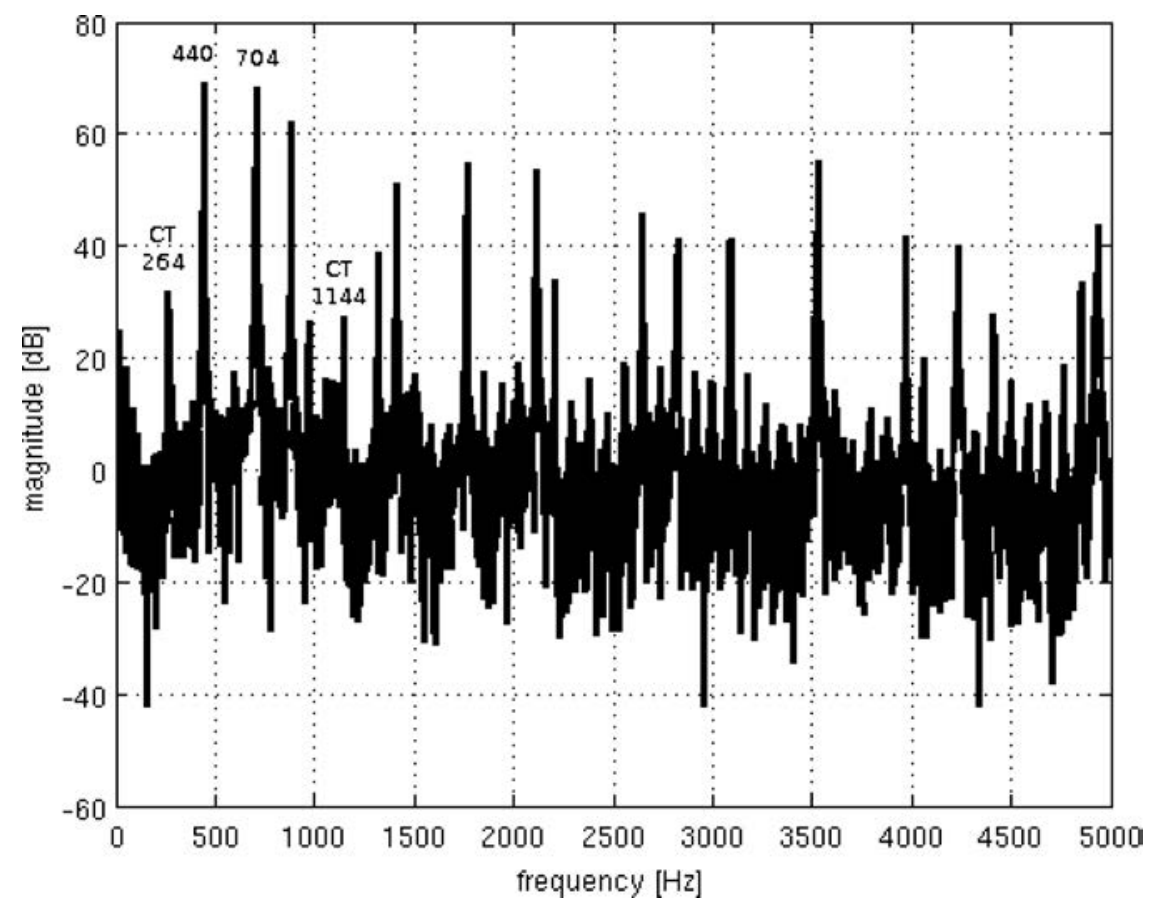

Fig. 3. Interval 5:8 (440 and $704 \mathrm{~Hz}$ ) played on a violin (method 1, with free vibrating strings and with sound post). The lower peaks occuring between the partial tones correspond to combination tones (for example CT $264 \mathrm{~Hz}$ and CT $1144 \mathrm{~Hz}$ ).

To obtain significant results, more measurement series have to be done. Especially the data of method 2 must be confirmed by further measurements. Due to the fact that changes in any part of the violin (see Subsec. 3.1) may cause major differences in the resonance behaviour, it is very difficult to determine the origin of combination tones. Nevertheless, the following intermediate results can be mentioned.

We expect that the sound post increases the nonlinearity in middle and high frequency regions whilst low combination tones are damped out. Another hypothesis is that the wood of the body of the violin has nonlinear properties. From a theoretical point of view the curvature of the violin plates could also be a source of nonlinear behaviour. Nonlinearities might appear in bodies where two 


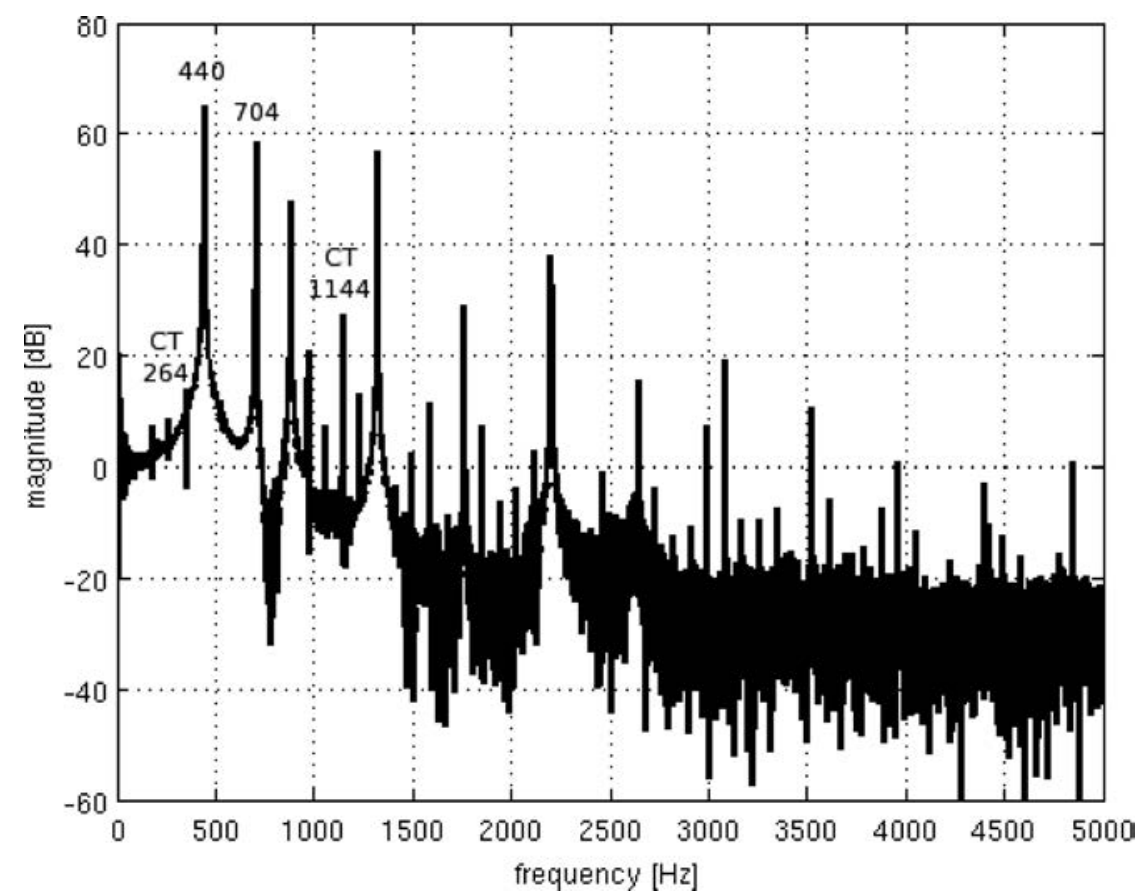

Fig. 4. Spectrum of the accelerometer signal when exciting the violin with an electrodynamic mini-shaker at frequencies 440 and $704 \mathrm{~Hz}$ (method 2, with free vibrating strings and sound post). Numerous combination tones were observed.

different elastic materials are in contact, but still have certain freedom to move independently. Such systems can easily be found in a violin. Namely the strings, the bridge or the sound post are possible sources of freely vibrating components that could hold potential nonlinear behaviour.

The execution of just musical intervals causes coincidence between partial and combination tones. This effect is comparable to a natural amplifier of the played notes, and subsequently must have an influence on the timbre and the volume of the sound. The simpler the interval ratio, the more combination tones coincide with partial tones.

\subsection{Violin, viola and violoncello}

Extending the experiment, viola and violoncello players were invited as well. To establish a basis for comparison the same intervals were played on all three instruments on the two analogous strings. The data of measurements showed that combination tones appear in all three instruments (see Fig. 5). The positions of combination tone peaks are determined by the distance (frequency ratio) of the played notes. The amplitudes of combination tones depend on the amplitudes of the partial tones and on the individual resonance behaviour of each instrument. Generally it can be observed that the violoncello tends to generate less extra- 

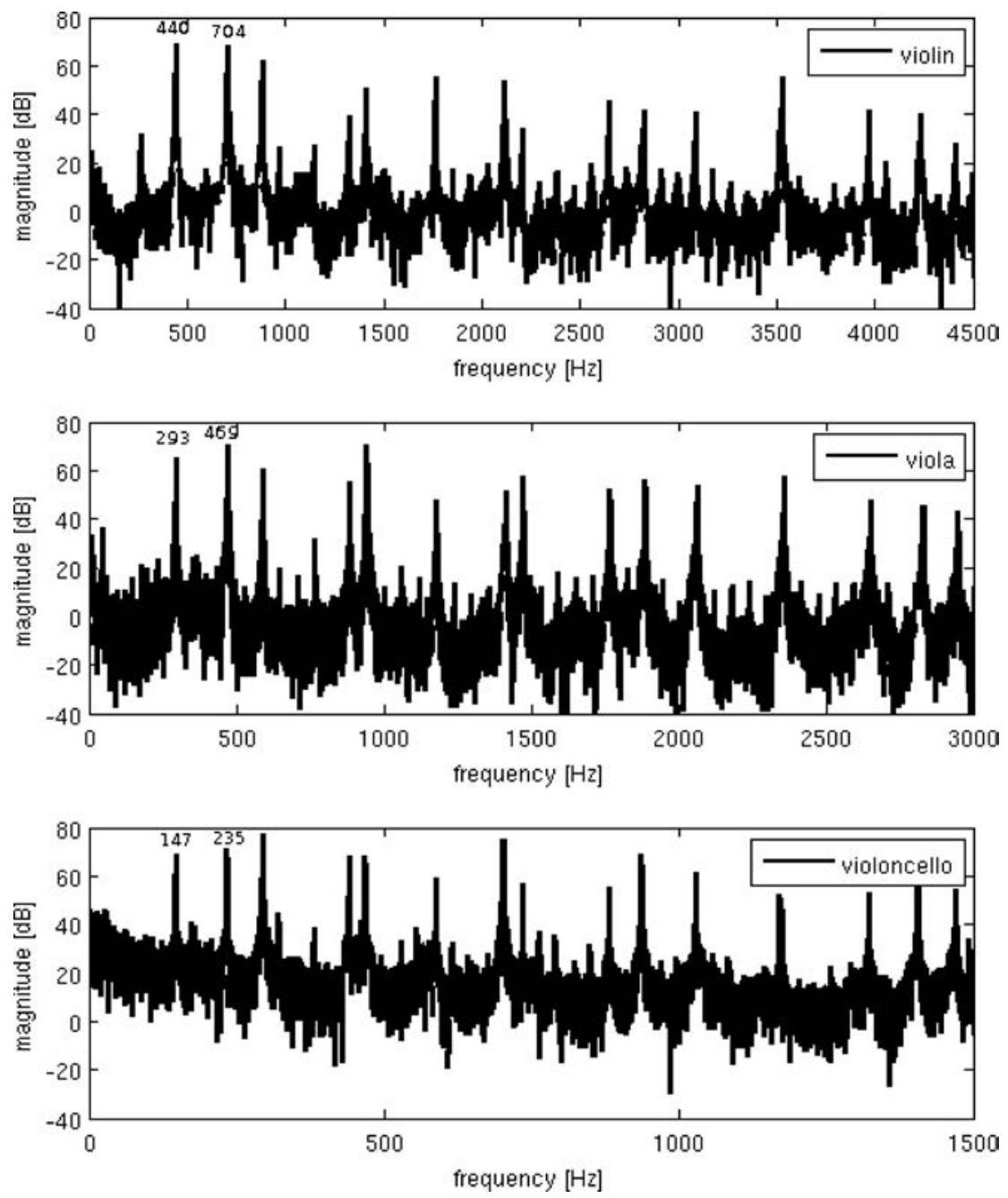

Fig. 5. Extra-aural combination tones generated in a violin, viola and violoncello. The three graphics represent the interval 5:8 played on analogous strings (violin; $\mathrm{a}^{\prime}$ and $\mathrm{f}^{\prime \prime}$ viola; $\mathrm{d}^{\prime}$ and b-flat ${ }^{\prime}$, violoncello; d and b-flat ${ }^{\prime}$. The frequencies marked in the spectra are rounded to the closest integer.

aural combination tones than the violin. Regarding the violin, a preliminary test showed that the wood tone (about 200-240 Hz) and the air resonance (about $290 \mathrm{~Hz}$ ) might favour the appearance of extra-aural combination tones in these frequency regions.

\section{3. 'Combination tone 1'}

When operating with just musical intervals, the lowest combination tone which may result coincides with the generator of the common harmonic series 
of the two notes. We therefore have chosen to term it 'combination tone 1'. In most musical intervals the combination tone 1 is equal to the first difference tone, e.g. this is the case for the interval 5:6 $(6-5=1)$. For other intervals such as $5: 8(8-5=3)$ this equivalence is not given. In this regard, the greatest common divisor (GCD) of the frequencies of the two primary tones is the more appropriate formula to calculate the combination tone 1 .

The linear representation of a frequency spectrum of a recorded simultaneous interval (see Fig. 6) shows that the partial tones (higher peaks) and the extraaural combination tones (lower peaks) are spaced at a regular distance of $110 \mathrm{~Hz}$. In other words, the peaks of combination tones are not randomly distributed, but appear in a pattern of equal distance which is determined by the greatest common divisor of the two primary tones (in this case $110 \mathrm{~Hz}$ ). This grid of equidistant frequencies may suggest the harmonic series of a pitch which corresponds to the combination tone 1 at $110 \mathrm{~Hz}$. This is similar to the "residual tone" phenomenon described by SCHOUTEN (1940, p. 290): "The pitch of the residue is [...] correlated [...] with the periodicity of the collective vibration form of the constituent harmonics". These observations fortify the assumption that the combination tone 1 has multiple origins; the nonlinear distortion of the ear, the

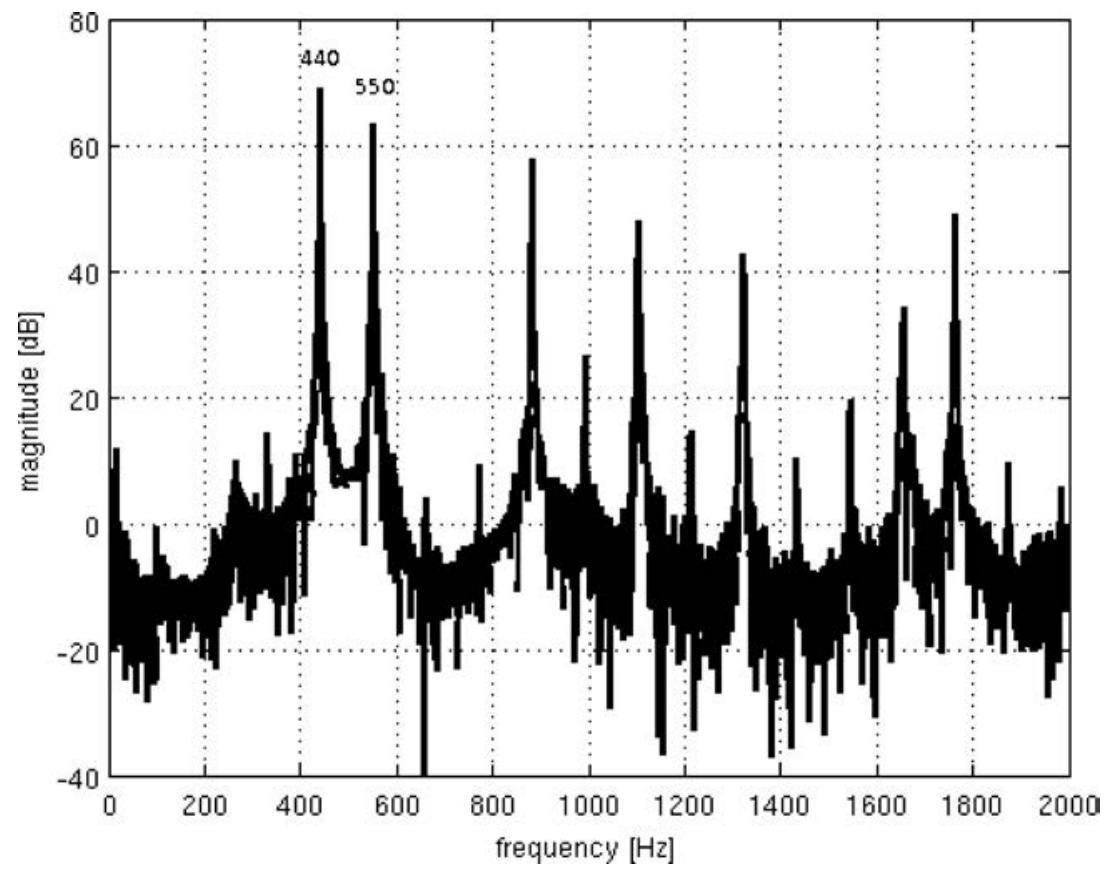

Fig. 6. Spectrum of the simultaneous interval 4:5 (440 and $550 \mathrm{~Hz}$ ). By filling in the blanks between partial tones, combination tones complete the series of equidistant frequencies that suggest the harmonic series of a virtual pitch corresponding to the combination tone 1 . In our example this "virtual pitch" is $110 \mathrm{~Hz}$, which is the greatest common divisor of $440 \mathrm{~Hz}$ and $550 \mathrm{~Hz}$. 
nonlinearity of the instrument and the ear's ability to perceive the collective of multiples of a frequency as one single pitch. The third explanation leads us to assume that not only partial tones but also combination tones (ECT or ICT) may have a significant influence on the strength of the combination tone 1 .

\subsection{Audibility of extra-aural combination tones}

Simultaneous intervals played on a violin generate both intra-aural and extraaural combination tones. Since both types of combination tones result in congruent pitches, it is difficult to ascertain from which type the hearing sensation derives, or to what extent both types contribute to the hearing sensation. In order to answer these questions, the following experiment was performed. An individual combination tone frequency (ECT) was extracted from the recorded sound (with the sound processing programm 'Jaco' (REuter, Griebel, 2010)). Subsequently, the audibility of the isolated combination tone was compared (by the authors) with the audibility when embedded in the original sound. It was observed that a combination tone clearly audible in the recording became significantly weaker when isolated from the original sound. These circumstances suggest that both mechanisms (ICT and ECT) are active in complex sounds. We may even assume that in most cases the intra-aural phenomenon has a stronger influence on the loudness of combination tones than the extra-aural phenomenon.
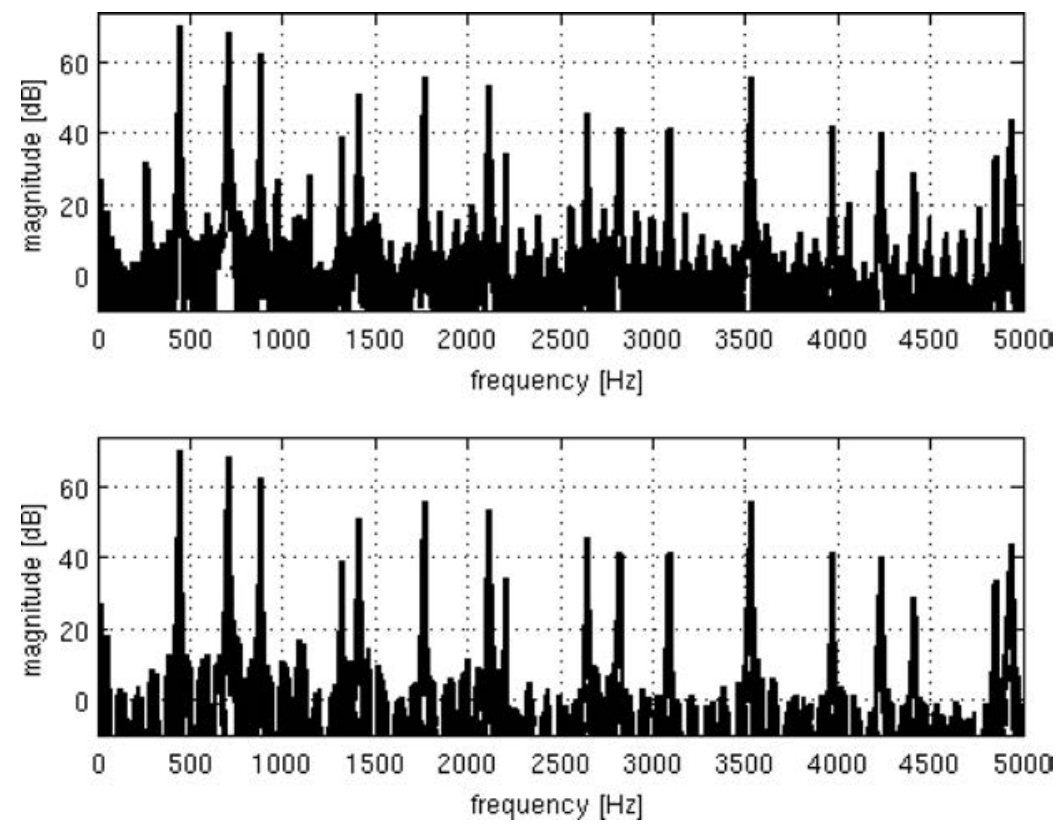

Fig. 7. Hearing test examples. Top: Interval 5:8 played on a violin in the original recording. Bottom: the same interval after removing the extra-aural combination tones with a sound processing program. 
We are currently in the process of performing a listening test which aims at investigating if extra-aural combination tones have an effect on the timbre of simultaneous intervals played on string instruments. Three recorded simultaneous intervals (one by a violin, shown in Fig. 7, one by a viola and one by a violoncello) and the same three examples modified by cutting out all the extra-aural combination tones from 0 up to $20000 \mathrm{~Hz}$ (with the sound processing programm 'Jaco') serve as test materials. The two different versions of each interval are then randomly combined to equal/equal-, different/different-, equal/differentand different/equal-pairs. In total, 60 pairs are played to the musicians who judge if any difference between the two sounds can be heard.

\subsection{Perspectives}

This study opens up further questions regarding the importance of combination tones in music performance and acoustics of string instruments.

- Do extra-aural combination tones affect the perception of simultaneous intervals played on string instruments?

- Are intra-aural combination tones more important in the performance of music than extra-aural combination tones?

- How important is the natural resonance of the instrument regarding the amplitude of particular combination tones?

- How does the appearance of combination tones of high quality instruments compare to that of low quality instruments?

- How many orders of combination tones need to be considered to devise a mathematical model for extra-aural combination tones generated by two frequencies?

- To what extent do extra-aural combination tones reinforce the partial tones in just musical intervals played on the violin?

Furthermore, it would be interesting to detect extra-aural combination tones in other musical instruments as well.

\section{References}

1. Ebeling M. (2007), Verschmelzung und neuronale Autokorrelation [in German], Peter Lang GmbH Europäischer Verlag der Wissenschaften, Frankfurt am Main.

2. HÄLlström G.G. (1819), De tonis combinationis, dissertatio physica [in Latin], University of Aboae.

3. Hällström G.G. (1832), Von den Combinationstönen [in German], Ann. Phys. Chem., 24, 438-466.

4. von Helmholtz H. (1856), Ueber Combinationstöne [in German], Ann. Phys. Chem., 99, $497-540$. 
5. von Helmholtz H. (1863), On the Sensations of Tone as a Physiological Basis for the Theory of Music, trans. by Alexander J. Ellis from the fourth (1877) edition, New York: Dover Publications, Inc., 1954. First German edition published Braunschweig: Verlag von F. Vieweg \& Sohn.

6. Husmann H. (1953), Vom Wesen der Konsonanz [in German], Müller-Thiergarten-Verlag, Heidelberg.

7. Krueger F. (1900), Beobachtungen an Zweiklängen [in German], Phil. Stud., 16, 307-379, $568-664$.

8. LOHRI A. (2010), Symmetrien in Partialtonstrukturen von Zweiklängen und die Entstehung von Kombinationstönen [in German], in: Symmetry: Art \& Science 2010. The Journal of the International Society for the Interdisciplinary Study of Symmetry, Editors: Lugosi/Nagy, Budapest, 154-157.

9. Онм G.S. (1839), Bemerkungen über Combinationstöne und Stösse [in German], Ann. Phys. Chem., 47, 463-466.

10. Plomp R. (1965), Detectability Threshold for Combination Tones, The Journal of the Acoustical Society of America, 37, 6, 1110-1123.

11. Reuter Ch., Griebel H. (2010), Jaco - High quality sinusoid tracks and envelopes, Proceedings of the Second Vienna Talk, Sept. 19-21, 2010, University of Music and Performing Arts Vienna, Austria, Retrieved Juin 10th, 2011: http://viennatalk.mdw.ac.at/papers/Pap_01_22_Reuter.pdf

12. Schouten J.F. (1940), The perception of pitch, Philips Technical Review, 5, 286-294.

13. Smoorenburg G.F. (1972), Audibility region of combination tones, J. Acoust. Soc. Amer., 52, 603-614.

14. Stumpf C. (1910), Beobachtungen über Kombinationstöne [in German], Z. Psychol., 55, 1-142 [Beitr. Akust. Musikwiss. 5, 1-142 (1910)].

15. Tartini G. (1754), Trattato di musica secondo la vera scienza dell'armonia [in Italian], Stamperia del Seminario, Padova.

16. Vieth G. (Dir.) (1805), Ueber Combinationstöne, in Beziehung auf einige Streitschriften über sie zweier englischer Physiker, Th. Young und Jo. Gough [in German], Ann. Phys., 21, 265-314.

17. Waetzmann E. (1906), Zur Frage nach der Objektivität der Kombinationstöne [in German], Ann. Phys., 20, 837-845.

18. Zwicker E., Feldtkeller R. (1967), Das Ohr als Nachrichtenempfänger [in German], S. Hirzel Verlag, Stuttgart. 